\title{
Using Personas to Promote Inclusive Education in an Online Course
}

\author{
Katie Stripe, Katie Dallison, Dallas Alexandrou \\ Imperial College London, UK
}

\begin{abstract}
Inclusion and diversity are themes at the forefront of education development and the subject of much institutional level policy. However, there are differences that can be made at the course or even module level by local teams that will both compliment institutional policy and have an immediate impact on students. This paper aims to describe the process taken to embed diversity and inclusion into an online career development short course. We will explain how user experience personas, created in the design phase of the course, developed into an integral part of the course curriculum and how they are used to show diversity to a fully asynchronous online cohort. We discuss how theories of pedagogy and design can be combined to have a positive impact on the sense of belong for all students. Finally, we explore how these theories can be applied to wider practice and offer suggestions for how other courses can use our process to embed elements of diversity into their programmes, and hopefully increase a sense of student belonging.
\end{abstract}

\section{Introduction}

Feeling included starts with being able to see other people with similar characteristics to your own. As digital education becomes more embedded in everyday curricula and not just something for distance students, we have an opportunity, and a moral obligation, to reflect on and update our modules, programmes, courses, and supplementary material so that they do not exclude, either overtly or subtly, any individual or group. Institutional approaches to inclusion and diversity often have a focus on a particular group and may overlook the theory of intersectionality, described by Kimberly Crenshaw in 1991 [1] as taking account of not only the group, but the various ways those groups "interact to shape the multiple dimensions" of the individuals experience.

This paper provides an account of how an online short course, Attributes and Aspirations (AA), focusing on career planning and key skills development, uses personas as a fundamental and integrated element of the curriculum narrative and in so doing, addresses issues of inclusivity and diversity within higher education, albeit at a micro, rather than a cross-institutional level. AA uses the principles of universal design to develop content, not from a viewpoint of specific inclusion, but with an absence of exclusion. The personas we have designed and integrated in AA are diverse, but subtly so. Critically, our aim was always to do this sensitively and in a way that is representative of our student cohort.

The essence of this paper is not about making our cohort more diverse - this is both accepted and welcomed - but for historical reasons the content we use in our curricula does not always reflect that diversity. This can have a negative impact on students, on their sense of belonging, learning, and ultimately on their future careers. We accept that while there are institutional issues, we do not have the capital to influence these on a macro level, but we can wield influence within a small sphere, within our control, and we propose the use of personas like those in AA as one way of doing this - with the hope that small scale, bottom-up changes can influence wider institutional activities and beyond.

\section{About us and the Programme}

The AA team consists of an academic sponsor, a project manager, a careers consultant, and a learning designer. We are currently: all female; all Caucasian; university educated to different levels; have lived, and worked in several countries; have varied professional backgrounds; are gay and straight; some of us have children and some of us have experience with neurodiversity. In a paper that intends to address issues of diversity it is important to know that we, as authors and contributors, are aware of our privilege and of our diversity, such as it is, and that we are all committed to equality, diversity, equity and inclusion in Higher Education and in life in general. Throughout the development process we have employed student testers, extensive student evaluations and input from academic colleagues.

In 2017 Imperial College introduced a new Learning and Teaching Strategy [2] which broadly aims to review, analyse and reinvent curricula, implement strong pedagogic models and update teaching methods, with a particular emphasis on interactive learning. Among the many opportunities presented by this strategy was the opportunity for 
departments to create projects and apply to the Pedagogy Transformation Fund for financial support. The Faculty of Medicine's Postgraduate Education Team, in collaboration with the Careers Service, seized this opportunity to create Attributes and Aspirations. AA is an elective, online, non-credit bearing short course for Master's students. The curriculum covers effective planning for professional futures, key skills development, pathways to $\mathrm{PhD}$ study or employment, and adaptation to new professional environments.

AA was designed using the principles of Universal Design for Learning, credited to David Rose and Anne Meyer at the Centre for Applied Special Technology, which apply architectural principles of accessibility to the learning sphere. A building with no steps designed for a wheelchair user will also benefit many others such as young parents using a pushchair, the visually impaired or those with minor mobility challenges. In the educational context the principles are the same, Universal Design doesn't design specifically for the impaired or the underrepresented but designs with the understanding that these groups and/or individuals form part of a diverse cohort. This aims to add flexibility into a curriculum by "designing courses with the intention of helping each student find the approach to acquiring, generating, and using new knowledge that is just right for him or her" [3]. AA allows students to select their own pathway through the course and to choose content which is relevant and timely for them. AA contains mixed media, accessible content, opportunities for personal reflections and the use of Plan: Me [4], a career planning tool designed to introduce structure in career exploration and decision making.

\section{Creating the AA Avatars}

We created personas as part of the initial design process which were then embedded in our programme and became known as our 'AA Avatars'. For the remainder of the paper, reference to personas will relate to the theoretical constructs common in user experience (UX) design, but the specific characters created for AA will be referred to as Avatars. We will discuss how we created, developed, and embedded these Avatars, how they enhance the diversity and inclusion of our course, and offer suggestions as to how readers may create and deploy their own.

Personas are a common practice in UX design and provide ways of considering the users of digital media to ensure the output meets their needs. They are "archetypical users whose goals and characteristics represent the needs of a larger group of users" [5] and allow designers a user's perspective, very similar to an educational needs analysis, but more personal. Using the team's experience with Imperial postgraduate medical students, knowledge of career development and trends in the labour market our students will be entering, we defined 3 archetypal students that reflect the cohorts to whom AA will be delivered.

After the initial creation of these personas the next logical step was to use them as characters in the course narrative, describing career progression and exemplar content such as CVs and job application forms. Once the decision to use them in course design was made, we consciously added a fourth student to provide gender balance - the 'AA Avatars' were born.

They naturally reflect our cohort in their backgrounds: one international student, a home student of international heritage, and a mature student returning from industry. As we further developed their backgrounds, they were given religion, sexuality, caring responsibilities, partners, and families together with hobbies and life history. This context could be introduced naturally as we created CVs and application documents, appropriate to the career development focus of the programme. By the way the AA Avatars are embedded in tasks throughout the course they also exhibit varied learning styles and behaviours which allow us, as educators, to offer our students options to make their own choices and decisions, by seeing how these applied to 'someone like them'. None of the diversity in our AA Avatars is overt but it is demonstrably evident and by weaving the Avatars through the content, we are giving students who are working alone, a companion or a reference point who is like them in some regard, even just by virtue of being a postgraduate student.

The AA Avatars were created initially as personas to help design a course that met students' needs as is typical for UX design. However, they began to take on an additional importance as they progressed from being simple personas to Avatars, linked to the course content. Consequently, they began to form an integral part of the Universal Design process and supported the creation of social inclusion content, complementing other design aspects which focus more on the physical needs of students. Each of the four Avatars have their own journey through the course. They appear in different modules and complete different activities, mimicking the variety of options available to students to work through the course in way that suits them.

\section{Belonging in a Digital Environment}

In their paper on student belonging Ahn and Davis [6] conclude that of the four domains of belonging in higher education; academic engagement, social engagement, surroundings and 
personal space, social engagement is the most important. However, they caution that surroundings and personal space are still important factors that can often be overlooked. When considering digital delivery of varying proportions of content, it follows that as students spend less time in a physical classroom or co-located with their classmates, that surroundings and personal space will become more relevant to their social engagement and sense of belonging.

From a teaching perspective the pedagogical ideal is often considered to be an environment which reflects the principles of social constructivism, "a theory of learning, not of instruction" [7], meaning that as educators we can only develop the environment and the content. The challenge for creating a socially constructivist environment for asynchronous online learners is providing a social element that is both dynamic and sustainable. There are ways of bringing social interaction into an online course, but they are rarely sufficiently reliable to be considered valuable (unless there are resources to always have a facilitator present). This means that Vygotsky's zone of proximal development [8] and Bundura's learning by imitation [9] must be contrived to exist where there is no classroom, and the students are geographically isolated from each other.

For courses like AA, and online delivery in general, the main channels for developing identity and confidence that come when students physically interact with their teacher and peers are either unavailable entirely or prohibitively resource intensive. Therefore, like echo3education's cartoon expert Echo, who is the 'more capable peer' that allows a mimicking of Vygotsky's zone of proximal development [10], we fake it.

\section{Discussion}

A recent study from the Open University showed that $58 \%$ of their [remote learning] students found studying in general helped with their sense of confidence and identity [11] which is encouraging for online course designers. Whilst there are clear challenges in developing online content that provides a social element, there are also opportunities. If we fake the social interaction we are not constrained by the demographics of the institution - we can reflect not only the cohort that we have but perhaps even the cohort we want, by developing content that is not constrained by the norms that have developed alongside the traditional classroom.

The University of Birmingham's framework for delivering LGBTQ inclusivity states that significant benefit is derived from the presence of people who identify as LGBTQ+ [12]. Not by explicit teaching, but by the inherent challenge to homophobia their inclusion facilitates. "It is these small changes that our Birmingham students have identified as crucial to improving their experience." Nowhere in AA do we explicitly state that one of our Avatars is from the LGBTQ community - this could come across as forced or as 'outing' a student for the sake of visible diversity. However, volunteering for an LGBT charity is mentioned in the Avatar's CV, and references are made to it as the Avatar works on skills such as prioritisation and time management.

Stonewall identifies "a limited curriculum that's not LGBT-inclusive, failing to engage or alienating LGBT students" as one of the common barriers for learning [13]. It is not hard to imagine that a limiting, non-representative curriculum could be a barrier to more than just LGBT students. This has led to the concept of curriculum decolonisation where institutions aim to move away from Eurocentricity of content, and projects such as "Why is my curriculum white?" [14]. We are no longer tied by the physical constraints of hard copies in libraries so we can, and should, look further afield for the academic content we use as core reading, and at the faces/backgrounds of students we use for exemplar content, case studies and promotional material. The exemplar content within AA is focussed on the Avatars and generated specifically to match their progression through university and into the world of work. Once again there are no explicit references to BAME students progressing into research careers, but it is there.

Most institutions have some form of widening participation process to address diversity and representation among their cohort, but the sobering reality pointed out by Fyfe et al [15] in their letter to the British Medical Journal is that we could be "actively recruiting under-represented students into a system in which they are likely to face discrimination, harassment, and systematic educational disadvantage." As those designing and delivering curriculum, we may not have the leverage to address these wider issues, but the broadening of content and diversification of examples is within our control. At the very least, students from minority backgrounds should see versions of themselves in the examples used to highlight content and in the case studies we use as the basis of courses. Building Avatars, like those in AA, could allow educators to achieve this, particularly if there is an awareness of an institutional widening participation agenda which can then be utilised to match the designed personas to underrepresented groups. It will be a small step, but definitely one taken in the right direction. Creating your own personas also gives you the freedom to create more content, as we have done to highlight other issues of access and inclusion. For example, caring responsibilities, or decisions relating to personal matters that influence work and studying. Such issues have been specifically built into our 
Avatars as we know that they are important to our cohort.

\section{Recommendations}

Our examples highlight specific areas relating to diversity and inclusion in our current cohort, but they can be extrapolated to encompass most underrepresented groups - something we intend to do as we develop both the course and our Avatars for delivery to other Faculties within Imperial College and beyond.

In some respects, because of AA's subject matter, it was natural for us to create Avatars for our course. Creating these diverse backgrounds in a scenario where a $\mathrm{CV}$ is the teaching tool means that the history is not forced. In other disciplines care would need to be taken to avoid tokenism but the opportunities for using Avatars in other subjects as the focus of a case study are broad and the principle AA uses of having them as a guide throughout a course, answering questions and asking 'fellow students' for help, could be universal. Like Echo, our Avatars act as the 'more competent peer' in some areas where they are being used to highlight the use of industry tools. Furthermore, as a career planning course, we are able to see our Avatars continue beyond their studies and into their new work environments - a process which could be replicated for most vocational subjects.

\section{Conclusion}

The academic year 2020/21 was the first year of full delivery for AA and initial feedback has been very positive with students commenting that they have enjoyed "reading about other students and their journey", and that they value "examples of how the modules can help each avatar in real life". With a focus on more practical aspects, a student stated, "the example skill set helped me to think about what skills I have developed, and the links were interesting". We had planned to do more extensive evaluation with our students, but the Covid-19 pandemic has meant that some of this has had to be postponed. What you see here is the theoretical basis of the inclusion of the Avatars and we hope to gather more student responses over time as well as working with student partners and academics from other faculties to expand the course. It is hoped that this explanation of our use of Avatars will inspire you to use similar approaches with your own cohorts and that it will act as a driver for change to enhance the learning experience for all students.

\section{References}

[1] Crenshaw, K. (1991). 'Mapping the Margins: Intersectionality, Identity Politics, and Violence against Women of Color'. Stanford Law Review 43(6): 1241-99.

[2] Buitendijk, S., (2017). 'Innovative Teaching for World Class Learning' Learning and Teaching Strategy. Imperial College London. https://www.imperial.ac.uk/media/imperi al-college/about/leadership-and-strategy/vp-education/ public/LearningTeachingStrategy.pdf (Access date: May 5, 2020).

[3] Rogers-Shaw, C., Carr-Chellman, D.J., and Choi, J., (2018). 'Universal Design for Learning: Guidelines for Accessible Online Instruction'. Adult Learning 29(1): 2031.

[4] Dallison, K. J., (2019) 'Plan: Me - a Practical Tool for Career Decision Making'. Journal of the National Institute for Career Education and Counselling 43(1): 26-32.

[5] Babich, N., (2017). 'Putting Personas to Work in UX Design: What They Are and Why They're Important'. Adobe Blog.https://blog.adobe.com/en/publish/2017/09/ 29/putting-personas-to-work-in-ux-design-what-they-are -and-why-theyre-important.html (Access date: January 11, 2021).

[6] Ahn, M. Y., Davis, H. H., (2020). 'Four Domains of Students' Sense of Belonging to University'. Studies in Higher Education 45(3): 622-34.

[7] Swan, K., (2005). 'A constructivist model for thinking about learning online'. Elements of Quality Online Education: Engaging Communities. 6.

[8] Vygotsky, L.S., (1978). Mind in Society: The Development of Higher Psychological Processes. Cambridge, MA: Harvard University Press.

[9] Bandura, A., (1977). Social Learning Theory. Englewood Cliffs, London : Prentice-Hall.

[10] King, A., (2018). 'Why Social Constructivism Is What Lone ELearners Need' ELearning Industry. https://elearningindustry.com/social-constructivism-loneelearners-need.

[11] Lister, K., (2020) 'Resources and Downloads'. Mental Wellbeing in the Curriculum. https://wellbeinginthecurricu lum.weebly.com/resources.html (Access date: January 13, 2021).

[12] Ward, N., and Gale, N., (2016). 'LGBTQ-Inclusivity in the Higher Education Curriculum: A Best Practice Guide'. University of Birmingham. https://intranet.birming ham.ac.uk/staff/teaching-academy/documents/public/lgbtbest-practice-guide.PDF (Access date: January 11, 2021).

[13] Budd, K., (2019). 'Delivering LGBT-Inclusive Higher Education. Academic Provision, Accommodation, Catering, Facilities, Induction, Recruitment, Registry, Societies, Sports and Student Services'. Stonewall. https://www.ucl.ac.uk/womens-health/sites/womens-health 
/files/delivering_lgbt_inclusive_higher_education-2019.pd f (Access date: January 11, 2021).

[14] National Union of Students. (2014). 'Why Is My Curriculum White?' UCL - Dismantling the Master's House. http://www.dtmh.ucl.ac.uk/videos/curriculumwhite/ (Access date: January 11, 2021).

[15] Fyfe, M. V., Kumar, S., Maini A., Horsburgh, J., Golding, B., (2020). 'Widening participation: moving from diversity to inclusion'; 368 :m966 doi:10.1136/bmj.m966.

\section{Acknowledgements}

The authors would like to acknowledge our academic sponsor, Dr Sophie Rutschmann who oversees all elements of the project. 